\title{
Different IGRs concentrations against maize stem borer (Chilo partellus Swinhoe) in field condition of Faisalabad- Pakistan
}

\author{
Muhammad Salman Hameed ${ }^{1 *}$, Saif-Ur-Rehman ${ }^{2}$, Nazeer Ahmed ${ }^{3}$, \\ Farman $\mathrm{Ali}^{4}$ and Saeed $\mathrm{Ahmed}^{5}$ \\ 1. Institute of Applied Ecology and Research Centre for Biodiversity and Eco-Safety, Fujian Agricultural and \\ Forestry University, Fuzhou 350002-China \\ 2. LIRR-Laboratory of insect Related Resources, Northwest A\&F University, Yangling-China \\ 3. Key Laboratory of Applied Entomology, Northwest A\&F University, Yangling-China \\ 4. Key Laboratory of Fungi and Micotoxin, Fujian Agricultural and Forestry University Fuzhou, Fujian-China \\ 5. State University of Londrina Centre of Agriculture Sciences Londrina, Parana (PR)-Brazil \\ *Corresponding author's email: msuleman2941@yahoo.com \\ Citation \\ Muhammad Salman Hameed, Saif-Ur-Rehman, Nazeer Ahmed, Farman Ali and Saeed Ahmed. Different IGRs \\ Concentrations against maize stem borer (Chilo partellus Swinhoe) in field condition of Faisalabad-Pakistan. Pure \\ and Applied Biology. Vol. 5, Issue 4, pp971-986. http://dx.doi.org/10.19045/bspab.2016.50123
}

Received: 04/04/2016

Revised: 22/08/2016

Accepted: 28/08/2016

Online First: 05/09/2016

\section{Abstract}

The experiment was conducted at the Youngwala experimental area of the Department of Agri. Entomology, University of Agriculture, Faisalabad in a Randomized Complete Block Design (RCBD), with 24 treatments excluding one control. The data for maize stem borer population was recorded after 3 days, 7 days and 14 days post IGRs application. The results obtained are concluded that all the insect growth regulators were equally effective against maize stem borer at different concentrations and on the numerical basis lowest stem borer population and its infestation was recorded in the pyriproxyfen ${ }^{\circledR}$ and priority ${ }^{\circledR}$ at $2 \mathrm{x}$ concentration and at concentration of field recommended concentration followed by other treatments concentrations. So, among the entire tested insect growth regulators pyriproxyfen ${ }^{\circledR}$ and priority ${ }^{\circledR}$ were the most effective IGRs against maize borer. Among the entire tested insect growth regulators viper@ and sitara ${ }^{\circledR}$ were the least effective IGRs against maize borer.

Keywords: Maize borer (Chilo partellus Swinhoe); Formulation; IGRs

\section{Introduction}

Agricultural gross domestic product and $85 \%$ of export revenue and employment to a total of 25 to $50 \%$ of the labor force, according to Pakistan's economy is built on the national level. Corn (L Egypt), popular Pakistani food, feed and fodder crops. Pakistan produced only $8,92 \mathrm{t}$ ha -1 , the
United States, Canada and 7.82 T, China and France, 7.14 tons of HA-1 [1] of 4.85 tons, and in Pakistan, corn planting 967,000 hectares, with an annual output of more than 3.0 , the average yield of $1970 \mathrm{~kg} \mathrm{HA}-1$ of the 1731 tons $6.4 \%$ of corn grain production in the country [2]. Agriculture being the backbone of Pakistan's economy employs 
$50 \%$ of the total labour force at national level, contributing 25 and $85 \%$ to GDP and export earnings, respectively. Maize (Zea mays L.) is a popular food, feed and fodder crop in Pakistan. Its yield in Pakistan is only $3.0 \mathrm{t} \mathrm{ha}^{-1}$ compared to USA $8.92 \mathrm{t} \mathrm{ha}^{-1}$, Canada $7.82 \mathrm{t} \mathrm{ha}^{-1}$, France $7.14 \mathrm{t} \mathrm{ha}^{-1}$ and China $4.85 \mathrm{t} \mathrm{ha}^{-1}$ [1] and in Pakistan, maize is grown over an area of 967 thousand hectares with an annual production of 1731 thousand tons with an average yield of 1970 $\mathrm{kg} \mathrm{ha}^{-1}$ [2]. Maize contributes about $6.4 \%$ of total cereal produce of the country. Maize or corn (maize), the grass family (Poaceae) plants alone. This is the cultivation of food crops around the world is not the most important. Corn for human nutrition and industrial products from the food and the raw materials necessary for the production of a lot of things, but not only. Corn starch, maltodextrin, corn oil, corn syrup, including industrial production and fermentation and distillation. In addition, most recently used as a biofuel. Wheat, grain crop after rice is the third annual ranking of Mecca. Irrigation and the Pakistani province of Punjab, but it is grown in almost all areas of the rain-fed areas. After the food source and the object of many industrial raw material, the yield has been cultivated mainly for the production of food is. Corn starch, 10\% protein, $4.80 \%$ fat, $9.50 \%$ fiber, $3.0 \%$, $1.70 \%$ sugar and $72 \%$ of ash, because they have a high nutritional value [3]. Because, as well as the king of food crops, "wheat for its high yield. Pakistan is the greatest population growth, food security issues. In the last two decades, the population (3\%) was offset by the increase in grain production. The expected growth rate of the corn wet milling and feed industries. With an annual output of 3,037 million tons of corn, and $2864 \mathrm{~kg} / \mathrm{ha}$, the average grain yield the 1,016 million hectares planted. Corn Pakistan, 66\% water; rainfed farming conditions. Mainly because of a good harvest of 20-25\% annual growth during the spring corn planting area, $(6-7 \mathrm{t} / \mathrm{ha})$ notice. Pakistan, corn is one of the success stories of agricultural prices. Seed and Pakistan, Egypt, the most important factor of production is limited. Improved seed and only $34 \%$. Grain drying and storage facilities, due to the volatile and uncertain market. In 2001, poultry, corn, feed grain in 2007 to $23 \%$ in Punjab has increased by 55\% [4]. Global corn (L Egypt), Pakistan and other countries in the long-term and the most important and popular grain crop production per unit area of great importance to the whole, and as such, it is a very versatile fruit to feed people food, fuel, animal feed, poultry and cattle wish. Corn nutritional value, but also a rich source of raw materials for the production of industrial products. Pakistan, more than the 1,022 million hectares, producing 35.6 million tonnes, $3483 \mathrm{~kg} / \mathrm{ha}$ average level of the corn planted in the area. Compared to the US average yield per unit area of less than $8990 \mathrm{~kg}$ [5]. Corn plays an important role in the economy of the country. High-yielding, yet per hectare / per cent of the maize yield hybrid varieties. Pakistan, agriculture, growth in the world's food and feed used for any purpose. In Pakistan, more nutrients due to higher food and fodder production, and its high-yield corn leaves and thick meat. Pakistan's growth, but it is always the Fund's Northwest Frontier Province and Punjab [6], about $98 \%$ of the district is the most important works. This is a food, feed and feed use and for wet milling, paper, textiles, clothing, a lot of the food processing industry, and the food industry may be able to use, as well as the use of raw materials. Its oil is used in pharmaceutical and humans and animals hypochlestermic [3]. Nutritional value, [7] and the corn starch (72\%) of the cells, protein (10\%), fiber ( $8.5 \%)$, petroleum (4.8), glucose $(3 \%)$ and more than gray o 'them (1.7\%). Approximately $64 \%$ of the 
corn-fed irrigation, under the rain [8]. Scientists around the world pay special attention to the development of safe and sustainable pest management techniques, the use of the serious consequences. Environmental control measures to suppress harmful Corn Borer and Flying Shot corn crops. Research, design, Sitara ${ }^{\circledR}$ (buprofezin), Viper@ (buprofezin), Lufenuron ${ }^{\circledR} \quad$ Pyriproxyfen ${ }^{\circledR} \quad$ Priority® (pyriproxyfen) and TRACK® (lufenuron) IGRS Corn Borer liked the sense of residual toxicity and effectiveness of the evaluation forms. The objective of this research was that to determine the effectiveness of Insect growth regulators against maize stem borer

\section{Materials and methods}

The experiment was conducted out under the field conditions, during year of 2011 at Youngwala experimental area of the department of Agricultural Entomology, University of Agriculture Faisalabad, to determine the effectiveness of Insect growth regulators against maize stem borer. The
IGRs which were used against maize borer at different concentrations in this experiment include, Viper ${ }^{\circledR}$ (buprofezin) 25WP Agri Top, Sitara® (buprofezin) 25WP Ali Akbar, Lufenuron ${ }^{\circledR} \quad$ (Lufenuron $\left.{ }^{\circledR}\right) \quad 5 \% \quad$ EC Syngenta, Pyriproxyfen $®$ (pyriproxyfen $®)$ $1.8 \%$ EC Kanzo, Priority® (pyriproxyfen) $10.8 \%$ EC Kanzo and Track® (lufenuron) used against the A hybrid maize cultivar, AAS-9732.

\section{Results}

The maize crop was treated with different concentrations of insect growth regulators when the pest population reached again at ETL. The details of the population count/percent are given as under with different intervals. The ANOVA parameters showed that the interaction of IGRs with concentrations had non-significant impact on infestation and all treatments had highly significant impact on infestation against maize borer before 24 hours of application of treatments (Table 1 and Figure 1).

Table 1. ANOVA regarding the percent infestation of maize stem borer before 24 hours of application

\begin{tabular}{|c|c|c|c|c|c|}
\hline Source & DF & SS & MS & F & P \\
\hline IGRs & 5 & 16.91247 & 3.382494 & 1.150932 & $0.343881^{\text {ns }}$ \\
\hline Concentrations (C) & 4 & 84.98822 & 21.24706 & 7.229554 & $0.000081^{* *}$ \\
\hline IGRs*C & 20 & 15.92378 & 0.796189 & 0.270912 & $0.998977^{\text {ns }}$ \\
\hline Error & 60 & 176.335 & 2.938917 & & \\
\hline Total & $\mathbf{8 9}$ & $\mathbf{2 9 4 . 1 5 9 5}$ & & & \\
${ }_{* *}^{*}=$ highly significant, ${ }^{\text {ns }}$ non-significant
\end{tabular}

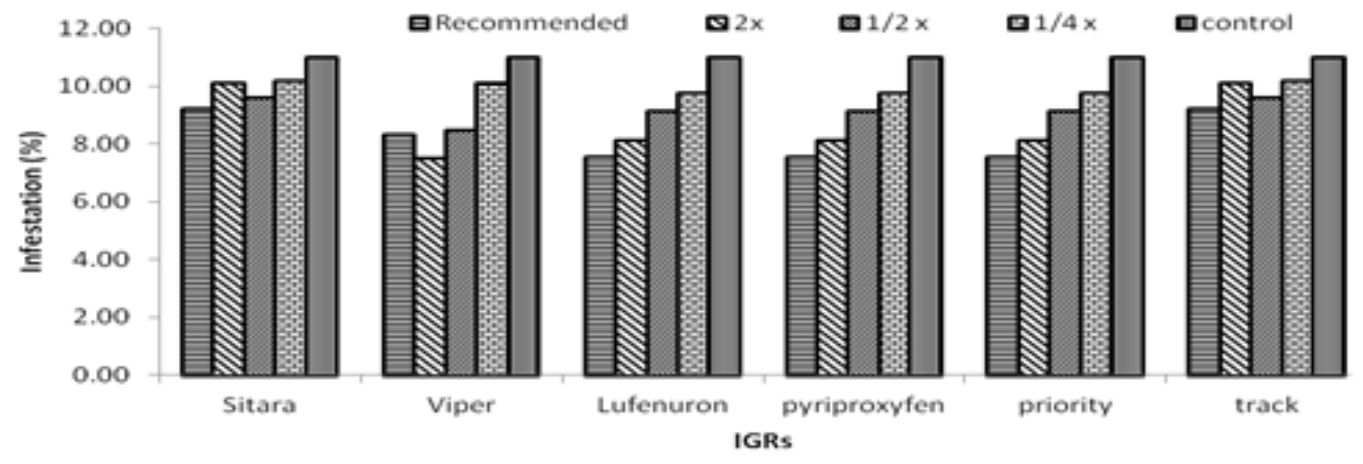

Figure 1. Infestation of maize stem borer 24 hours 
The ANOVA parameters showed that treatments induced highly significant $(\mathrm{P}<0.01)$ variation in percent infestation of maize stem borer and interaction of IGRs with concentrations had non-significant impact on infestation as shown in (Table 2). The (Figure 2) showed that those plots which were treated with Sitara ${ }^{\circledR}$ showed 4.0-10.0\% infestation at different concentrations. Minimum $4.0 \%$ infestation was recorded in those plots where Sitara ${ }^{\circledR}$ was applied at concentration of 2x of FRD; whereas at rest of the concentration Sitara $\AA$ explained $7.8-10.0 \%$ infestation at 3 days post treatment intervals. Viper® demonstrated $3.7-8.8 \%$ infestation at different concentrations and at 3 days post treatment interval. Minimum infestation $3.7 \%$ was observed in those plots where Viper® was sprayed at concentration of $2 \mathrm{x}$ of FRD. Viper® at rest of concentrations demonstrated approximately $5.5-8.5 \%$ infestation by maize borer at three days post treatment interval. Lufenuron ${ }^{\circledR}$ demonstrated $4.0-7.0 \%$ infestation at different concentrations and at 3 days post treatment interval. Minimum infestation $4.0 \%$ was observed in those plots where Viper® was sprayed at concentration of $2 \mathrm{x}$ of FRD. Lufenuron ${ }^{\circledR}$ at rest of concentrations demonstrated approximately 5.9-7.0\% infestation by maize borer at three days post treatment interval. A percentage infestation was recorded in the range of 2.5$10.0 \%$ in plots where Pyriproxyfen ${ }^{\circledR}$ was sprayed at different concentrations. Pyriproxyfen ${ }^{\circledR}$ demonstrated minimum infestation $(2.5 \%)$ at FRD, whereas 5.5$10.0 \%$ for the rest of concentrations at post treatment intervals of three days. Percentage infestation of maize borer ranged from 2.5$10.0 \%$ in those plots where Priority ${ }^{\circledR}$ was sprayed at different concentrations. Priority® demonstrated minimum infestation (2.5\%) when applied at FRD. However, $\quad$ Priority® ${ }^{\circledR} \quad$ explained approximately $5.5-10.0 \%$ infestation when applied at $2 \mathrm{x}$ of FRD, 1/2x of FRD and 1/4x of FRD for a post treatment interval of three days. The plots which were treated with Track ${ }^{\circledR}$ at different concentrations showed percentage infestation in the range of 4.0$8.9 \%$ at 3 days of post treatment intervals. Track® demonstrated minimum infestation when applied at concentration of $2 \mathrm{x}$ of FRD. Rest of this concentration of Track $®$ explained approximately 7.8-8.9\% infestation at a post treatment interval of 3 days.

Table 2. ANOVA regarding the percent infestation of maize stem borer after 3 days of application

\begin{tabular}{|l|c|c|c|c|c|}
\hline Source & DF & SS & MS & F & P \\
\hline IGRs & 5 & 24.51667 & 4.903334 & 0.671987 & $0.646224^{\mathrm{ns}}$ \\
\hline Concentrations $(C)$ & 4 & 438.0726 & 109.5181 & 15.00914 & $0.000000^{* *}$ \\
\hline IGRs*C & 20 & 42.8506 & 2.14253 & 0.293627 & $0.99821^{\mathrm{ns}}$ \\
\hline Error & 60 & 437.8059 & 7.296766 & & \\
\hline Total & $\mathbf{8 9}$ & $\mathbf{9 4 3 . 2 4 5 8}$ & & & \\
\hline
\end{tabular}

${ }^{* *}=$ highly significant, ${ }^{\mathrm{ns}}$ non-significant 


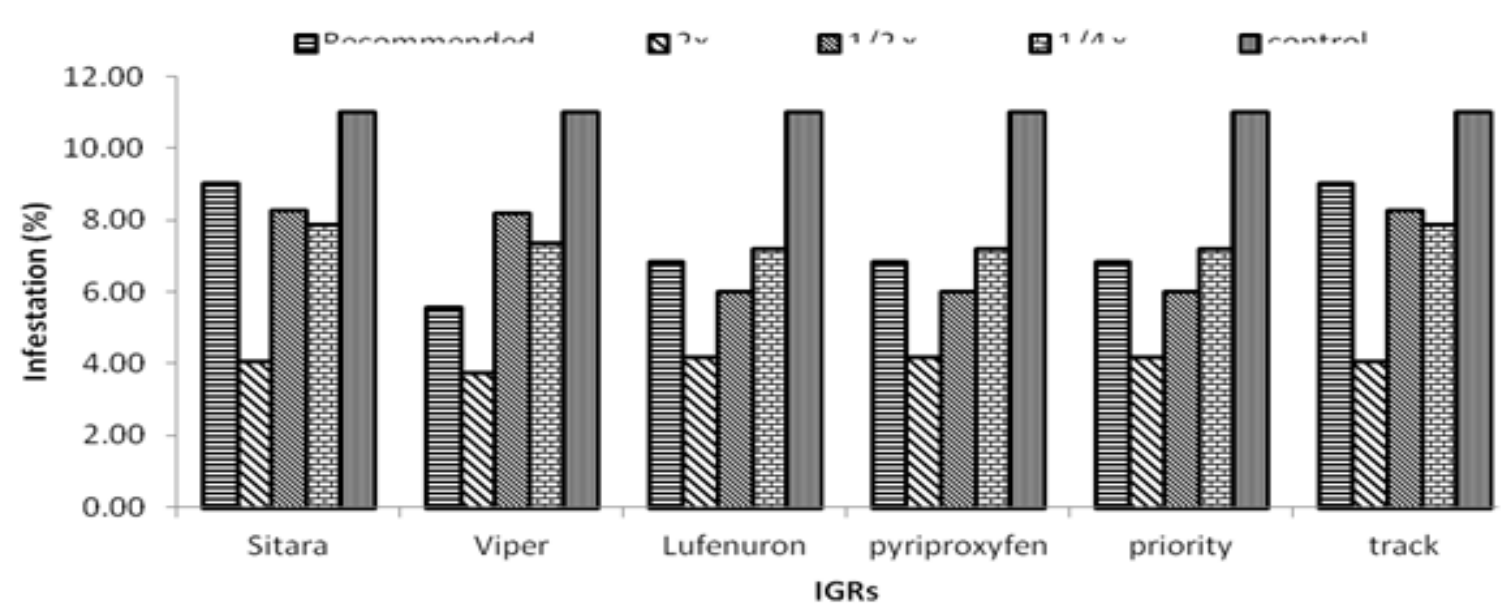

Figure 2. Infestation of maize stem borer 3 days after application

\section{Days of application}

The ANOVA parameters showed that treatments induced highly significant $(\mathrm{P}<0.01)$ variation in percent infestation of maize stem borer and combination of IGRs with concentrations had nonsignificant on infestation of maize borer as shown in (Table 3). The (Figure 3) showed that those plots which were treated with Sitara ${ }^{\circledR}$ showed $1.33-6.45 \%$ infestation at different concentrations. Minimum $1.33 \%$ infestation was recorded in those plots where Sitara ${ }^{\circledR}$ was applied at concentration of $1 / 2 \mathrm{x}$ of FRD; whereas at rest of the concentration Sitara ${ }^{\circledR}$ explained $4.0-6.45 \%$ infestation at 7 days post treatment intervals. Viper® demonstrated $1.66-5.5 \%$ infestation at different concentrations and at 7 days post treatment interval. Minimum infestation $1.66 \%$ was observed in those plots where Viper® was sprayed at concentration of $1 / 2 x$ of FRD. Viper® at rest of concentrations demonstrated approximately $2.1-5.5 \%$ infestation by maize borer at seven days post treatment interval. $\quad$ Lufenuron ${ }^{\circledR}$ demonstrated $0.33-4.45 \%$ infestation at different concentrations and at 7 days post treatment interval. Minimum infestation $0.33 \%$ was observed in those plots where Viper ${ }^{\circledR}$ was sprayed at concentration of $1 / 2 x$ of FRD. Lufenuron ${ }^{\circledR}$ at rest of concentrations demonstrated approximately $2.0-4.45 \%$ infestation by maize borer at seven days post treatment interval. A percentage infestation was recorded in the range of $0.3-4.4 \%$ in plots where Pyriproxyfen ${ }^{\circledR}$ was sprayed at different concentrations. Pyriproxyfen ${ }^{\circledR}$ demonstrated minimum infestation $(0.3 \%)$ at 1/2x of FRD, whereas $2.0-4.4 \%$ for the rest of concentrations at post treatment intervals of seven days. Percentage infestation of maize borer ranged from $0.33-4.0 \%$ in those plots where Priority® was sprayed at different concentrations. Priority® demonstrated minimum infestation $(0.33 \%)$ when applied at $1 / 2 \mathrm{x}$ of FRD. However, Priority® explained approximately $2.0-4.0 \%$ infestation when applied at FRD, 2x of FRD and $1 / 4 \mathrm{x}$ of FRD for a post treatment interval of seven days. The plots which were treated with Track ${ }^{\circledR}$ at different concentrations showed percentage infestation in the range of $1.33-6.45 \%$ at 7 days of post treatment intervals. Track $®$ demonstrated minimum infestation when applied at concentration of $2 \mathrm{x}$ of FRD. Rest of this concentration of Track® explained approximately $4.0-6.45 \%$ infestation at a post treatment interval of 7 days. 
Table 3. ANOVA regarding the percent infestation of maize stem borer after 7 days of application

\begin{tabular}{|l|c|c|c|c|c|}
\hline Source & DF & SS & MS & F & P \\
\hline IGRs & 5 & 20.72267 & 4.144533 & 0.803689 & $0.551521^{\text {ns }}$ \\
\hline Concentrations (C) & 4 & 1049.693 & 262.4232 & 50.88788 & $0.000000^{* *}$ \\
\hline IGRs*C & 20 & 29.16733 & 1.458367 & 0.2828 & $0.998619^{\text {ns }}$ \\
\hline Error & 60 & 309.4133 & 5.156889 & & \\
\hline Total & $\mathbf{8 9}$ & $\mathbf{1 4 0 8 . 9 9 6}$ & & & \\
\hline
\end{tabular}

${ }^{*}=$ highly significant, ${ }^{\mathrm{ns}}$ nonsignificant

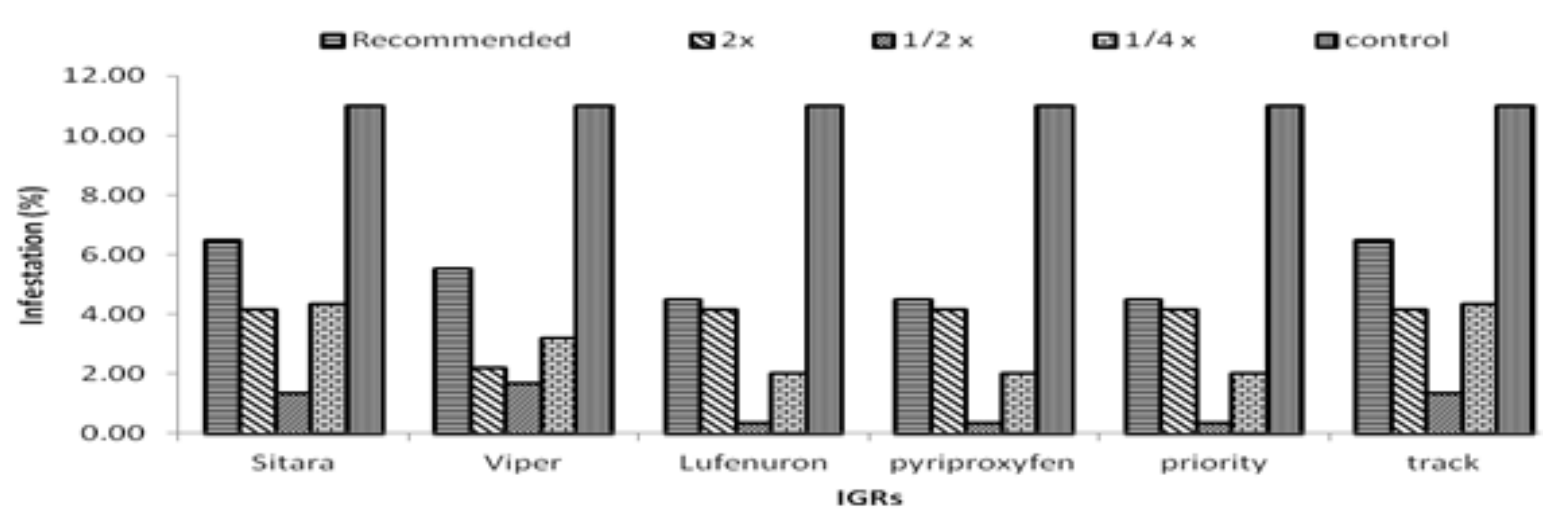

Figure 3. Infestation of maize stem borer 7 days after application

\section{4 days of application}

The ANOVA parameters showed that treatments induced highly significant $(\mathrm{P}<0.01)$ variation in percent infestation of maize stem borer and combination of IGRs with concentrations had nonsignificant on infestation of maize borer as shown in (Table 4). The (Figure 4) showed that those plots which were treated with Sitara ${ }^{\circledR}$ showed 1.33-4.0\% infestation at different concentrations. Minimum 1.33\% infestation was recorded in those plots where Sitara ${ }^{\circledR}$ was applied at concentration of $2 x$ of FRD; whereas at rest of the concentration Sitara ${ }^{\circledR}$ explained $2.7-4.0 \%$ infestation at 14 days post treatment intervals. Viper® demonstrated $0.66-3.65 \%$ infestation at different concentrations and at 14 days post treatment interval. Minimum infestation $0.66 \%$ was observed in those plots where Viper ${ }^{\circledR}$ was sprayed at concentration of $2 \mathrm{x}$ of FRD. Viper® at rest of concentrations demonstrated approximately 3.0-3.65\% infestation by maize borer at 14 days post treatment interval. $\quad$ Lufenuron ${ }^{\circledR}$ demonstrated 1.33-4.0\% infestation at different concentrations and at 14 days post treatment interval. Minimum infestation $1.33 \%$ was observed in those plots where Viper ${ }^{\circledR}$ was sprayed at concentration of $2 x$ of FRD. Lufenuron ${ }^{\circledR}$ at rest of concentrations demonstrated approximately $1.5-4.0 \%$ infestation by maize borer at 14 days post treatment interval. A percentage infestation was recorded in the range of 1.3$4.0 \%$ in plots where Pyriproxyfen ${ }^{\circledR}$ was sprayed at different concentrations. Pyriproxyfen ${ }^{\circledR}$ demonstrated minimum infestation (1.3\%) at $2 \mathrm{x}$ of FRD, whereas $1.5-4.0 \%$ for the rest of concentrations at post treatment intervals of 14 days. Percentage infestation of maize borer ranged from $1.33-4.2 \%$ in those plots where Priority ${ }^{\circledR}$ was sprayed at different concentrations. Priority ${ }^{\circledR}$ demonstrated minimum infestation $(1.33 \%)$ when applied at $2 x$ of FRD. However, Priority ${ }^{\circledR}$ explained approximately $1.5-4.2 \%$ infestation when 
applied at FRD, 1/2x of FRD and 1/4x of FRD for a post treatment interval of 14 days. The plots which were treated with Track $®$ at different concentrations showed percentage infestation in the range of $1.33-4.0 \%$ at 14 days of post treatment intervals. Track $®$ demonstrated minimum infestation when applied at concentration of $2 x$ of FRD. Rest of this concentration of Track ${ }^{\circledR}$ explained approximately $2.76-4.0 \%$ infestation at a post treatment interval of 14 days.

Table 4. ANOVA regarding the percent infestation of maize stem borer after 14 days of application

\begin{tabular}{|c|c|c|c|c|c|}
\hline Source & DF & SS & MS & F & P \\
\hline IGRs & 5 & 6.334333 & 1.266867 & 0.347658 & $0.881781^{\text {ns }}$ \\
\hline Concentrations (C) & 4 & 1113.486 & 278.3716 & 76.39176 & $0.000000^{* *}$ \\
\hline IGRs*C & 20 & 15.96844 & 0.798422 & 0.219106 & $0.999784^{\text {ns }}$ \\
\hline Error & 60 & 218.64 & 3.644 & & \\
\hline Total & $\mathbf{8 9}$ & $\mathbf{1 3 5 4 . 4 2 9}$ & & & \\
\hline
\end{tabular}

${ }^{* *}=$ highly significant, ${ }^{\mathrm{ns}}$ nonsignificant

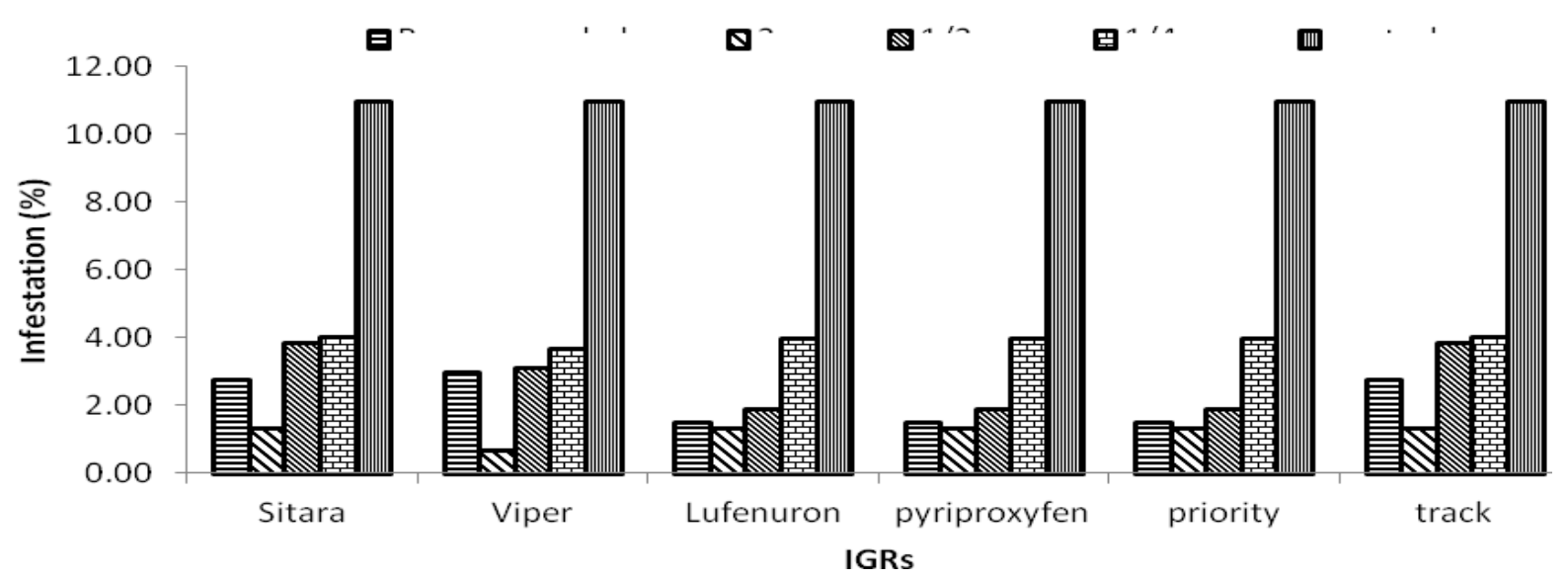

Figure 4. Infestation of maize stem borer 14 days application

The ANOVA parameters showed that all the treatments on reduction in percent infestation had significant impact on their infestation. But the combination of IGRs with concentrations had nonsignificant impact on reduction infestation after 3 days interval as shown in (Table 5).

Table 5. ANOVA parameters regarding the reduction in percent infestation after 3 days of application

\begin{tabular}{|l|c|c|c|c|l|}
\hline Source & DF & SS & MS & F & P \\
\hline IGRs & 5 & 516.1903 & 103.2381 & 0.05022 & 0.9983 \\
\hline Concentrations (C) & 4 & 25382.04 & 6345.511 & 3.086736 & $0.0223^{*}$ \\
\hline IGRs*C & 20 & 9192.635 & 459.6317 & 0.223585 & 0.9997 \\
\hline Error & 60 & 123344.1 & 2055.735 & & \\
\hline Total & $\mathbf{8 9}$ & $\mathbf{1 5 8 4 3 5}$ & & & \\
\hline
\end{tabular}

$*=$ significant 
The ANOVA parameters showed that all the treatments on reduction in percent infestation had highly significant impact on their infestation. But the combination of

Table 6. ANOVA parameters regarding the reduction in percent infestation after 7 days application

\begin{tabular}{|l|c|c|c|c|c|}
\hline Source & DF & SS & MS & F & P \\
\hline IGRs & 5 & 820.0632 & 164.0126 & 0.217509 & 0.9537 \\
\hline Concentrations (C) & 4 & 84062.17 & 21015.54 & 27.87028 & $0.0000^{* *}$ \\
\hline IGRs*C & 20 & 3098.275 & 154.9138 & 0.205443 & 0.9998 \\
\hline Error & 60 & 45242.91 & 754.0486 & & \\
\hline Total & $\mathbf{8 9}$ & $\mathbf{1 3 3 2 2 3 . 4}$ & & & \\
\hline
\end{tabular}

$* *$ highly significant

The ANOVA parameters showed that all the treatments on reduction in percent infestation had highly significant impact on their infestation. But the combination of

Table 7. ANOVA parameters regarding the reduction in percent infestation after 14 days of application

\begin{tabular}{|c|c|c|c|c|c|}
\hline Source & DF & SS & MS & F & P \\
\hline IGRs & 5 & 508.8373 & 101.7675 & 0.299319 & 0.9112 \\
\hline Concentrations (C) & 4 & 83854.54 & 20963.63 & 61.65829 & $0.0000^{* *}$ \\
\hline IGRs*C & 20 & 1834.143 & 91.70713 & 0.269729 & 0.9990 \\
\hline Error & 60 & 20399.82 & 339.997 & & \\
\hline Total & $\mathbf{8 9}$ & $\mathbf{1 0 6 5 9 7 . 3}$ & & & \\
\hline
\end{tabular}

*** highly significant

Regarding the efficacy of different concentrations at 3 days post treatment interval almost all the concentrations demonstrated different percentage infestation. At 3 days post treatment interval, 1/4x of FRD demonstrated $7.41 \%$ infestation and $25.52 \%$ reduction in infestation, $1 / 2 \mathrm{x}$ of FRD showed $7.10 \%$ infestation and $22.82 \%$ reduction in infestation. FRD explained $7.03 \%$ infestation and $14.78 \%$ reduction in infestation and $2 \mathrm{x}$ concentration of FRD demonstrated $4.05 \%$ infestation and $53.39 \%$ reduction in infestation at 3 days post treatment interval. Overall in $2 \mathrm{x}$ of FRD explained maximum (53.39) reduction in infestation at 3 days post treatment interval. Regarding the efficacy of different
IGRs with concentrations had nonsignificant impact on reduction infestation after 7 days interval as shown in (Table 6).

IGRs with concentrations had nonsignificant impact on reduction infestation after 14 days interval as shown in (Table 7). concentrations at 7 days post treatment interval almost all the concentrations demonstrated different percentage infestation. At 7 days post treatment interval, FRD demonstrated $5.30 \%$ infestation and showed $35.75 \%$ reduction in infestation, 2x of FRD showed $3.80 \%$ infestation and $56.27 \%$ reduction in infestation. 1/4x of FRD explained $2.97 \%$ infestation and $70.15 \%$ reduction in infestation and 1/2x concentration of FRD reduction in infestation at 7 days post treatment interval. Overall in $1 / 2 x$ of FRD and $1 / 4 \mathrm{x}$ of FRD explained maximum $(90.43 \%$ and $70.15 \%)$ reduction in infestation at 7 days post treatment interval respectively. Regarding the efficacy of demonstrated $0.88 \%$ infestation and $90.43 \%$ 
different concentrations at 14 days post treatment interval almost all the concentrations demonstrated different percentage infestation. At 14 days post treatment interval, $1 / 4 \mathrm{x}$ of FRD demonstrated $3.95 \%$ infestation and showed $60.30 \%$ reduction in infestation, $1 / 2 \mathrm{x}$ of FRD showed $2.74 \%$ infestation and $70.21 \%$ reduction in infestation. FRD explained $2.06 \%$ infestation and $75.03 \%$ reduction in infestation and $2 \mathrm{x}$ concentration of FRD demonstrated $1.22 \%$ infestation and $85.96 \%$ reduction in infestation at 14 days post treatment interval. Overall in 2x of FRD and FRD explained maximum $(85.96 \%$ and $75.03 \%$ ) reduction in infestation at 14 days post treatment interval respectively.

Regarding the efficacy of different IGRs at different post treatment interval, almost all the IGRs demonstrated similar percentage infestation. At 3 days post treatment interval, Sitara ${ }^{\circledR}$ and Track ${ }^{\circledR}$ demonstrated $8.02 \%$ infestation and $20.03 \%$ reduction in infestation. Viper ${ }^{\circledR}$ explained $7.15 \%$ infestation and $21.25 \%$ reduction in infestation. Pyriproxyfen ${ }^{\circledR}$ and Lufenuron ${ }^{\circledR}$ explained 7.02 infestations and $23.02 \%$ reduction in infestation at 3 days post treatment interval. Priority ${ }^{\circledR}$ showed $6.66 \%$ in infestation and $26.97 \%$ reduction in infestation. Overall, Priority ${ }^{\circledR}$ explained maximum (26.97) reduction in infestation at 3 days post treatment interval.

Regarding the efficacy of different IGRs at different post treatment interval, almost all the IGRs demonstrated similar percentage infestation. At 7 days post treatment interval, Sitara ${ }^{\circledR}$ and Track $®$ demonstrated $5.45 \%$ infestation and $48.05 \%$ reduction in infestation. Viper ${ }^{\circledR}$ showed 4.70 percentage infestation and $44.21 \%$ reduction in percentage infestation. Pyriproxyfen ${ }^{\circledR}$, Priority ${ }^{\circledR}$ and Lufenuron ${ }^{\circledR}$ explained 4.38 , 4.38 and $4.38 \%$ infestation and 51.97, 51.97 and $51.97 \%$ reduction in infestation respectively at 7 days post treatment interval. Overall, Pyriproxyfen ${ }^{\circledR}$, Priority ${ }^{\circledR}$ and Lufenuron ${ }^{\circledR}$ explained maximum (51.97\%) reduction in infestation at 7 days post treatment interval. Regarding the efficacy of different IGRs at different post treatment interval, almost all the IGRs demonstrated similar percentage infestation. At 14 days post treatment interval, Sitara ${ }^{\circledR}$ demonstrated same percentage infestation $(4.59 \%)$ and $54.23 \%$ reduction in infestation. Track ${ }^{\circledR}$ showed infestation $(4.46 \%)$ and reduction in percentage infestation (55.53\%). Viper ${ }^{\circledR}$ explained $4.28 \%$ infestation and $52.86 \%$ reduction in infestation at 14 days post treatment interval. Pyriproxyfen ${ }^{\circledR}, \quad$ Priority ${ }^{\circledR}$ and Lufenuron ${ }^{\circledR}$ showed same percentage $(3.94 \%)$ and $56.79 \%$ reduction in percentage. Overall, Pyriproxyfen ${ }^{\circledR}$, Priority ${ }^{\circledR}$ and Lufenuron ${ }^{\circledR}$ explained maximum $(56.79 \%)$ reduction in infestation at 14 days post treatment interval.

The ANOVA parameters showed that the interaction of IGRs with concentrations had nonsignificant impact on infestation of maize borer before 24 hours of second application and their treatments had highly significant impact on population fluctuation of maize stem borer as shown in (Table 8). In all treatments, maximum number of larvae of maize borer ranged from 1.67 to 2.67 larvae/five plants. 
Table 8. ANOVA regarding the population of larvae of maize stem borer before the second application

\begin{tabular}{|l|c|c|c|c|c|}
\hline Source & DF & SS & MS & F & P \\
\hline IGRs & 5 & 0.355556 & 0.071111 & 0.188235 & $0.965962^{\text {ns }}$ \\
\hline Concentrations (C) & 4 & 1240.956 & 310.2389 & 821.2206 & $0.000000^{* *}$ \\
\hline IGRs*C & 20 & 1.977778 & 0.098889 & 0.261765 & $0.999199^{\text {ns }}$ \\
\hline Error & 60 & 22.66667 & 0.377778 & & \\
\hline Total & $\mathbf{8 9}$ & $\mathbf{1 2 6 5 . 9 5 6}$ & & & \\
\hline
\end{tabular}

${ }^{* *}=$ highly significant, ${ }^{\mathrm{ns}}$ nonsignificant

The ANOVA parameters showed that treatments had highly significant impact on reducing the population of maize borer after 24 hours of second application of treatments (Table 9). The plots which were treated with Sitara ${ }^{\circledR}$ showed $0.66-2.33$ larvae/5plants at different concentrations. Minimum larval density/5 plants 0.66 was recorded in those plots where Sitara ${ }^{\circledR}$ was applied at concentration of 2x of FRD; whereas at rest of the concentration Sitara ${ }^{\circledR}$ explained larvae/5plants at post treatment intervals ranging from 1.66 to 2.33 larvae/5 plants. Viper® demonstrated $\quad 0.66-2.33$ larvae/5 plants at different concentrations at post treatment interval. Minimum larval density $0.66 / 5$ plants were observed in those plots where Viper ${ }^{\circledR}$ was sprayed at concentration of $2 \mathrm{x}$ of FRD. Viper ${ }^{\circledR}$ at rest of concentrations demonstrated approximately 1.66-2.33 larvae/5 plants of maize borer at post treatment interval. Larval density was recorded in the range of 0.33-1.66 larval/5plants in plots where Lufenuron ${ }^{\circledR}$ was sprayed at different concentrations. Lufenuron ${ }^{\circledR}$ demonstrated minimum infestation (0.33\%) at concentration of $1 / 4 \mathrm{x}$ of FRD, whereas $0.67-1.66$ on when larval density was observed for the rest of concentrations at post treatment intervals. Larval density was recorded in the range of 0.33-1.67 larval/5plants in plots where Pyriproxyfen ${ }^{\circledR}$ was sprayed at different concentrations. Pyriproxyfen ${ }^{\circledR}$ demonstrated minimum infestation $(0.33 \%)$ at concentration of $1 / 2 \mathrm{x}$ of FRD, whereas 0.66-1.66 on when larval density was observed for the rest of concentrations at post treatment intervals. Larval density of maize borer ranged from 0.33-1.66 larvae/5plants in those plots where Priority® was sprayed at different concentrations. Priority ${ }^{\circledR}$ demonstrated larval density (0.33/5plants) when applied at concentration of $1 / 2 x$ of FRD. However, Priority ${ }^{\circledR}$ explained approximately 0.66-1.66 larvae/5plants when applied at FRD, 2x of FRD and 1/4x of FRD for a post treatment interval. The plots which were treated with Track® at different concentrations showed larval density in the range of 0.66-2.33 larvae/5palnts at post treatment intervals. Track ${ }^{\circledR}$ demonstrated minimum larval density when applied at concentration of $2 x$ of FRD. Rest of this concentration of Track® explained approximately 1.66-2.33 larvae/5palnts at post treatment interval. 
Table 9. ANOVA regarding the population of larvae of maize stem borer after the application

\begin{tabular}{|l|c|l|l|l|l|}
\hline Source & DF & SS & MS & F & P \\
\hline IGRs & 5 & 8.1 & 1.62 & 6.075 & $0.000129^{* *}$ \\
\hline Concentrations (C) & 4 & 1390 & 347.5 & 1303.125 & $0.000000^{* *}$ \\
\hline IGRs*C & 20 & 14.4 & 0.72 & 2.7 & $0.001588^{* *}$ \\
\hline Error & 60 & 16 & 0.266667 & & \\
\hline Total & $\mathbf{8 9}$ & $\mathbf{1 4 2 8 . 5}$ & & & \\
\hline
\end{tabular}

= highly significant

The ANOVA parameters showed that all treatments had highly significant impact on larval population of maize borer but only interaction of IGRs between concentrations showed nonsignificant impact against larval density of maize borer as shown in (Table 10). Regarding the efficacy of different concentrations at post treatment interval almost all the concentrations demonstrated the different percent reduction in larvae/5plants and larval density/5 plants. At post treatment interval, $1 / 4 \mathrm{x}$ of FRD demonstrated 1.66 larval density/5 plants and 6.21 reduction in larvae/5plants, $1 / 2 \mathrm{x}$ of FRD showed 1.33 larval density/5 plants and 24.85 reduction in larvae/5 plants. FRD explained 1.16 larval density/5 plants and 22.66 reductions in larvae/5 plants and $2 x$ concentration of FRD demonstrated 0.66 larval density/5 plants and 64.89 reductions in larvae/5 plants at post treatment interval. Overall in 2x of FRD explained maximum $(64.89 \%)$ reduction in larvae/5 plants at post treatment interval (Table 11).

Table 10. ANOVA regarding the reduction in number of larvae on infested plants after application

\begin{tabular}{|l|c|c|c|c|c|}
\hline Source & DF & SS & MS & F & P \\
\hline IGRs & 5 & 36138.89 & 7227.778 & 3.212346 & $0.013^{*}$ \\
\hline Concentrations (C) & 4 & 35555.56 & 8888.889 & 3.950617 & $0.006^{* *}$ \\
\hline IGRs*C & 20 & 63444.44 & 3172.222 & 1.409877 & 0.153 \\
\hline Error & 60 & 135000 & 2250 & & \\
\hline Total & $\mathbf{8 9}$ & $\mathbf{2 7 0 1 3 8 . 9}$ & & & \\
\hline
\end{tabular}

$* *=$ highly significant

Table 11. Larval population per five plants of maize borer before and after second application at different concentrations and its reduction percentage

\begin{tabular}{|l|c|c|c|}
\hline Concentrations & $\begin{array}{l}\text { No. of larvae } \\
\text { before application }\end{array}$ & $\begin{array}{l}\text { No. of larvae after } \\
\text { application }\end{array}$ & $\begin{array}{l}\text { Reduction in population } \\
(\%) \text { and reduction means }\end{array}$ \\
\hline Control $\left(\mathbf{C}_{\mathbf{0}}\right)$ & $11.00^{\mathrm{a}}$ & $11.00^{\mathrm{a}}$ & $0.00\left(0.00^{\mathrm{ab}}\right)$ \\
\hline FRD $\left(\mathbf{C}_{\mathbf{1}}\right)$ & $1.50^{\mathrm{c}}$ & $1.16^{\mathrm{c}}$ & $22.66\left(8.33^{\mathrm{ab}}\right)$ \\
\hline $\mathbf{2 x}$ of FRD $\left(\mathbf{C}_{\mathbf{2}}\right)$ & $1.88^{\mathrm{b}}$ & $0.66^{\mathrm{d}}$ & $64.89\left(44.44^{\mathrm{b}}\right)$ \\
\hline $\mathbf{1} \mathbf{2} \mathbf{x}$ of FRD $\left(\mathbf{C}_{\mathbf{3}}\right)$ & $1.77^{\mathrm{bc}}$ & $1.33^{\mathrm{c}}$ & $24.85\left(27.78^{\mathrm{ab}}\right)$ \\
\hline $\mathbf{1} \mathbf{4} \mathbf{x}$ of FRD $\left(\mathbf{C}_{\mathbf{4}}\right)$ & $1.72^{\mathrm{bc}}$ & $1.66^{\mathrm{b}}$ & $6.21\left(-11.11^{\mathrm{a}}\right)$ \\
\hline CVC & 0.314 & 0.308 & \\
\hline
\end{tabular}

$\mathrm{CVC}=$ critical value for comparison, $\mathrm{FRD}=$ field recommended dose 
Regarding the efficacy of different IGRs at post treatment interval almost all the IGRs demonstrated similar percent reduction in larvae/5plants and larval density/5 plants. At post treatment interval, Viper®, Sitar ${ }^{\circledR}$ and Track® demonstrated 3.46 larval density $/ 5$ plants and 5.46, 0.0 and $1.98 \%$ reduction in larvae/5plants. Lufenuron ${ }^{\circledR}$, Pyriproxyfen $®$ and Priority® showed $2.86,2.86$ and 2.86 larval density/5 plants and 20.55, 20.55 and $20.55 \%$ reduction in larvae/5 plants respectively. Overall in Lufenuron $\AA$,
Pyriproxyfen ${ }^{\circledR}$ and Priority® explained maximum $(20.55 \%$ reduction in larvae/5 plants) at post treatment interval.

The ANOVA parameters showed that interaction of IGRs with concentrations had nonsignificant impact but only the concentrations showed highly significant impact on tunnel length before second application. In all treatments, tunnel length (cm) ranging from $2.36 \mathrm{~cm}$ to $3.26 \mathrm{~cm}$ (Table 12).

Table 12. ANOVA regarding the tunnel lengths $(\mathrm{cm})$ of maize stem borer before the application

\begin{tabular}{|l|c|c|c|c|c|}
\hline Source & DF & SS & MS & F & P \\
\hline IGRs & 5 & 0.064889 & 0.012978 & 0.019959 & $0.999829^{\text {ns }}$ \\
\hline Concentrations (C) & 4 & 1114.599 & 278.6497 & 428.5454 & $0.000000^{* *}$ \\
\hline IGRs*C & 20 & 1.338444 & 0.066922 & 0.102922 & $1^{\text {ns }}$ \\
\hline Error & 60 & 39.01333 & 0.650222 & & \\
\hline Total & $\mathbf{8 9}$ & $\mathbf{1 1 5 5 . 0 1 6}$ & & & \\
\hline
\end{tabular}

${ }^{* *}=$ highly significant, ${ }^{\mathrm{ns}}$ non-significant

The ANOVA parameters showed that treatments had highly significant impact on reducing the tunnel length of maize borer and the interaction of IGRs and concentrations had nonsignificant impact on reducing the tunnel length as shown in (Table 13). The plots which were treated with Sitara ${ }^{\circledR}$ showed 0.6-2.1 tunnel length (cm) at different concentrations. Minimum tunnel length 0.6 was recorded in those plots where Sitara ${ }^{\circledR}$ was applied at concentration of $2 \mathrm{x}$ of FRD; whereas at rest of the concentration Sitara ${ }^{\circledR}$ explained tunnel length at post treatment intervals ranging from 1.0 to 2.1 tunnel length. Viper® demonstrated 0.45-2.1 tunnel length $(\mathrm{cm})$ at different concentrations at post treatment interval. Minimum tunnel length $0.45 \mathrm{~cm}$ was observed in those plots where Viper $®$ was sprayed at concentration of $2 \mathrm{x}$ of FRD. Viper ${ }^{\circledR}$ at rest of concentrations demonstrated approximately 0.73-2.1 tunnel length by maize borer at post treatment interval. Tunnel length was recorded in the range of 0.6-1.96 tunnel length $(\mathrm{cm})$ in plots where Lufenuron ${ }^{\circledR}$ was sprayed at different concentrations. Lufenuron ${ }^{\circledR}$ demonstrated minimum tunnel length (0.66) at concentration of $2 \mathrm{x}$ of FRD, whereas 0.91.96 on when tunnel length was observed for the rest of concentrations at post treatment intervals. Tunnel length was recorded in the range of 0.66-1.96 tunnel length $(\mathrm{cm})$ in plots where Pyriproxyfen ${ }^{\circledR}$ was sprayed at different concentrations. Pyriproxyfen ${ }^{\circledR}$ demonstrated minimum tunnel length (0.66) at concentration of $2 \mathrm{x}$ of FRD, whereas 0.91.96 on when tunnel length was observed for the rest of concentrations at post treatment intervals. Larval density of maize borer ranged from 0.6-1.9 tunnel length $(\mathrm{cm})$ in those plots where Priority® was sprayed at different concentrations. Priority® demonstrated tunnel length $0.6 \mathrm{~cm}$ when applied at concentration of $2 x$ of FRD. However, $\quad$ Priority ${ }^{\circledR} \quad$ explained approximately 0.9-1.96 tunnel length when applied at FRD, 1/2x of FRD and 1/4x of 
FRD for a post treatment interval. The plots which were treated with Track® at different concentrations showed larval density in the range of 0.6-2.1 tunnel length $(\mathrm{cm})$ at post treatment intervals. Track ${ }^{\circledR}$ demonstrated minimum larval density when applied at concentration of $2 \mathrm{x}$ of FRD. Rest of this concentration of Track ${ }^{\circledR}$ explained approximately 1.06-2.1 tunnel length at post treatment interval.

Table 13. ANOVA regarding the tunnel lengths $(\mathrm{cm})$ of maize stem borer after the application

\begin{tabular}{|l|c|l|l|l|l|}
\hline Source & DF & SS & MS & F & P \\
\hline IGRs & 5 & 0.645 & 0.129 & 0.319715 & $0.899231^{\text {ns }}$ \\
\hline Concentrations $(C)$ & 4 & 1373.466 & 343.3664 & 851.0028 & $0.000000^{* *}$ \\
\hline IGRs*C & 20 & 1.485556 & 0.074278 & 0.184091 & $0.999944^{\text {ns }}$ \\
\hline Error & 60 & 24.20907 & 0.403484 & & \\
\hline Total & $\mathbf{8 9}$ & $\mathbf{1 3 9 9 . 8 0 5}$ & & & \\
\hline
\end{tabular}

${ }^{* *}=$ highly significant, ${ }^{\text {ns }}$ non-significant

The ANOVA parameters showed that all treatments had highly significant impact on tunnel length of maize borer but the interaction between IGRs and concentrations showed nonsignificant impact against tunnel length of maize borer as shown in (Table 14). Regarding the efficacy of different concentrations at post treatment interval almost all the concentrations showed significant decrease in tunnel length and percent reduction in tunnel length. At post treatment interval, $1 / 4 \mathrm{x}$ of FRD demonstrated 1.91 tunnel length and $16.95 \%$ reduction in tunnel length, FRD showed 1.83 tunnel length and $15.66 \%$ reduction in tunnel length. 1/2x of FRD explained 0.92 tunnel length and $64.20 \%$ reduction in tunnel length and $2 \mathrm{x}$ concentration of FRD demonstrated 0.59 tunnel length and $67.75 \%$ reduction in tunnel length at post treatment interval. Overall in $2 x$ of FRD and 1/2x of FRD explained maximum $(67.75$ and $64.20 \%)$ reduction in tunnel length $(\mathrm{cm})$ at post treatment interval respectively as shown in (Table 15).

Table 14. ANOVA regarding the reduction in tunnel length $(\mathrm{cm})$ on infested plants after the second application

\begin{tabular}{|l|c|c|c|c|c|}
\hline Source & DF & SS & MS & F & P \\
\hline IGRs & 5 & 2334.633 & 466.9265 & 0.538635 & 0.7462 \\
\hline Concentrations (C) & 4 & 54570.03 & 13642.51 & 15.73766 & $0.0000^{* *}$ \\
\hline IGRs*C & 20 & 7451.02 & 372.551 & 0.429766 & 0.9805 \\
\hline Error & 60 & 52012.21 & 866.8702 & & \\
\hline Total & $\mathbf{8 9}$ & $\mathbf{1 1 6 3 6 7 . 9}$ & & & \\
\hline
\end{tabular}

$* *=$ highly significant 
Table 15. Tunnel length $(\mathrm{cm})$ before and after application and its percent reduction at different concentrations

\begin{tabular}{|l|c|c|c|}
\hline Concentrations & $\begin{array}{l}\text { Tunnel length } \\
\text { before application }\end{array}$ & $\begin{array}{l}\text { Tunnel length } \\
\text { after application }\end{array}$ & $\begin{array}{l}\text { Reduction in Tunnel length } \\
(\%) \text { and reduction means }\end{array}$ \\
\hline Control $\left(\mathbf{C}_{\mathbf{0}}\right)$ & $11.00^{\mathrm{a}}$ & $11.00^{\mathrm{a}}$ & $0.00\left(0.00^{\mathrm{b}}\right)$ \\
\hline FRD $\left(\mathbf{C}_{1}\right)$ & $2.17^{\mathrm{bc}}$ & $1.83^{\mathrm{b}}$ & $15.66\left(11.46^{\mathrm{b}}\right)$ \\
\hline 2x of FRD $\left(\mathbf{C}_{2}\right)$ & $1.83^{\mathrm{c}}$ & $0.59^{\mathrm{d}}$ & $67.75\left(60.88^{\mathrm{a}}\right)$ \\
\hline $\mathbf{1} / \mathbf{2} \times$ of FRD $\left(\mathbf{C}_{\mathbf{3}}\right)$ & $2.57^{\mathrm{b}}$ & $0.92^{\mathrm{c}}$ & $64.20\left(55.42^{\mathrm{a}}\right)$ \\
\hline $\mathbf{1} / \mathbf{4}$ of FRD $\left(\mathbf{C}_{4}\right)$ & $2.30^{\mathrm{b}}$ & $1.91^{\mathrm{b}}$ & $16.95\left(16.02^{\mathrm{b}}\right)$ \\
\hline CVC & 0.414 & 0.309 & \\
\hline
\end{tabular}

$\mathrm{CVC}=$ critical value for comparison, $\mathrm{FRD}=$ field recommended dose

Regarding the efficacy of different IGRs at post treatment interval almost all the IGRs demonstrated similar percent reduction in tunnel length $(\mathrm{cm})$. At post treatment interval, Sitar ${ }^{\circledR}$ and Track ${ }^{\circledR}$ demonstrated 3.36 tunnel lengths $(\mathrm{cm})$ and $16.20 \%$ reduction in tunnel length $(\mathrm{cm})$. Lufenuron ${ }^{\circledR}$ and Priority ${ }^{\circledR}$ showed 3.23 tunnel lengths $(\mathrm{cm})$ and $18.22 \%$ reduction in tunnel length $(\mathrm{cm})$. Viper ${ }^{\circledR}$ explained 3.20 tunnel lengths (cm) and $19.60 \%$ reductions in tunnel lengths $(\mathrm{cm})$. Pyriproxyfen ${ }^{\circledR}$ demonstrated 3.13 tunnel lengths $(\mathrm{cm})$ and $20.75 \%$ reduction in tunnel lengths $(\mathrm{cm})$ at post treatment interval. Overall in Pyriproxyfen ${ }^{\circledR}$ explained maximum $(20.75 \%)$ reduction in tunnel lengths $(\mathrm{cm})$ at post treatment interval.

\section{Discussion}

Pyriproxyfen ${ }^{\circledR}$ control applications, and this is the best performance of the damage this insect growth regulator priority ${ }^{\circledR}$ maize diver (IGR) have all decreased. For this reason, it has been tested to outperform the poison. [9, 12-17] and these also revealed with the results of [18]. They IGR punctulatus fallen $0.05 \mathrm{ppm} 0.01 \mathrm{ppm} 0.1$ $\mathrm{ppm}$ at the full adult dose of four different doses of pyriproxyfen months and their immature stage of 1 or 2 months to deal with the results anofeles, 20,002 ppm. Death of tested insects was observed at the pupal stage and at adult emergence and most effective IGRs (pyriproxyfen ${ }^{\circledR}$ ) against maize also compatible with the results of [19] and [20] when they used pyriproxyfen ${ }^{\circledR}$ against resistant strains of Tribolium castaneum, susceptible strains of Rhyzopertha dominica and Sitophilus oryzae and for the suppression of emergence of Aedes togoi respectively pyriproxyfen ${ }^{\circledR}$ showed best results against these insects.

These results observation TRACK $® 1,667$ larvae, the larvae population decline and population in accordance with 0.000 priority ${ }^{\circledR}$, and in the case of five factories $[21,22]$. When they investigated the effect of IGRs (pyriproxyfen and buprofezin) against egg laying production of citrus mealy bug (Planococcus citri). The result showed that pyriproxyfen actually lowered the egg production of citrus mealy bug and these results also revealed with the results of [23] when they evaluated the buprofezin ${ }^{\circledR}$ and pyriproxyfen ${ }^{\circledR}$ residues against $B$. tabaci eggs. Both IGRs reduced $B$. tabaci egg fertility, especially the higher rate of pyriproxyfen ${ }^{\circledR}$ and both rates of buprofezin ${ }^{\circledR}$ but also buprofezin ${ }^{\circledR}$ and pyriproxyfen ${ }^{\circledR}$ results against maize borer were not compatible with these results and these IGRs are dose dependent [24-26].

\section{Conclusion}

Insect growth regulators were equally effective against maize stem borer at different concentrations and on the numerical basis lowest stem borer population and its infestation was recorded 
in the pyriproxyfen $\AA$ and priority $\AA$ at $2 x$ concentration and at concentration of field recommended concentration followed by other treatments concentrations. So, among the entire tested insect growth regulators pyriproxyfen ${ }^{\circledR}$ and priority ${ }^{\circledR}$ were the most effective IGRs against maize borer.

\section{Authors' contributions}

Performed the experiments: MA Abbas, Analyzed the data: SU Rehman \& N Ahmed,. Contributed reagents/ materials/ analysis tools: MS Hameed \& Farman Ali, Wrote the paper: S.U Rehman, MS Hameed, N Ahmed.

\section{References}

1. Anonymous (2003). Food and Agriculture Organization Available on website: http:// faostat.fao.org/faostat/collections?versi on=ext\&hasbulk=0\&subset=agriculture

2. Government of Pakistan (2001). Economic Survey of Pakistan. Min. Food Agric. Livest pp.24.

3. Chaudhary AR (1983). Maize in Pakistan. Agric. Res. Coord. Board, Univ Agri Fsd. Pak. pp: 43-44.

4. Tariq M \& Iqbal H (2010). Maize in Pakistan - An overview. Kasetsart J (Nat Sci) 44: 757- 763.

5. Anonymous (2006). Area and production of other major Kharif and Rabi crops. Economic survey of Pakistan 2005-06. Ministry of Food, Agriculture and Livestock. Federal Bureau of Statistics $15 \mathrm{pp}$.

6. Anonymous (2007). Agricultural statistic of Pakistan, Min. of Food, Agri. Livestock, Agric Livestock Div (Econ Wing), Islamabad.

7. Chaudhary FM (1994). Kharif cereals crop prod. National Book Foundation, Islamabad. pp: 252-260.

8. Nazir S (1994). Crop Protection. National Book Foundation, Islamabad. pp: 261271.
9. Suhail A, Arif MJ \& Yazdani MS (2000). Comparative efficacy of some insecticides against insect pest complex of maize. Pak J Biol Sci 3(6):10521053.

12. Mashwani AM, Ullah F, Sattar S, Ahmad S \& Khan MA (2011). Efficacy of different insecticides against maize stem borer, $C$. partellus Swinhoe (Lepidoptera: Pyralidae) at Peshawar and Swat valleys of Khyber Pakhutunkhwa, Pakistan. Sarhad J Agric 27(3).

13. Palumbo JC, Horowitz AR \& Prabhaker $N$ (2001). Insecticidal control and resistance management for Bemisia tabaci. Crop, Protect 20: 739-765.

14. Jambulingam P, Sadanandane C, Doss PSB, Subramanian S \& Zaim M (2008). Field evaluation of an insect growth regulator, pyriproxyfen $0.5 \%$ GR against Culex quinquefasciatus, the vector of Bancroftian filariasis in Pondicherry, India. Acta Tropica 107: 20-24.

15. Arthur FH, Liu S, Zhao B \& Phillips TW (2009). Residual efficacy of pyriproxyfen and hydroprene applied to wood, metal and concrete for control of stored-product insects. Pest Manag Sci 65: 791-797.

16. Nasr HM, Badawy $M$ \& Rabea EI (2010). Toxicity and biochemical study of two insect growth regulators, buprofezin and pyriproxyfen, on cotton leafworm Spodoptera littoralis. Pesticide Biochem Physiol 98 (2): 198205.

17. Athanassiou CG, Arthur FH, Kavallieratos NG \& Throne JE (2011). Efficacy of Pyriproxyfen for Control of Stored-Product Psocids (Psocoptera) on Concrete Surfaces. J Econ Entomol 104(5): 1765-1769.

18. Oberlander H, Silhacek DL, Shaaya E \& Ishaaya I (1997). Current status and 
future perspectives of the use of insect growth regulators for the control of stored product insects. J Stored Prod Res 33: 1-6.

19. Kostyukovsky M, Chen B, Atsmi S \& Shaaya E (2000). Biological activity of two juvenoids and two ecdysteroids against three stored product insects. Ins Biochem Mole Bio 30: 891-897.

20. Lee DK (2001). Field evaluation of an insect growth regulator, pyriproxyfen, against Aedes togoi larvae in brackish water in South Korea. J Vec Eco 26(1): 39-42.

21. Cloyd RA (2003). Effect of insect growth regulators on citrus mealy bug (Planococcus citri) egg production. Hort Sci 38(7): 1397-1399.

22. James GD (2004). Effect of buprofezin on survival of immature stages of Harmonia axyridis, Stethorus punctum picipes (Coleoptera: Coccinellidae), Orius risticolor (Hemiptera: Hnthocoridae), and Geocoris spp. (Hemiptera: Heocoridae). J Eco Entomol 97(3): 900-904.
23. Liu TX \& Stansly PA (2004). Lethal and sublethal effects of two insect growth regulators on adult Delphastus catalinae (Coleoptera: Coccinellidae), a predator of whiteflies (Homoptera: Aleyrodidae). Biol Cont 30: 298-305.

24. Naranjo SE, Ellsworth PC \& Haglar JR (2004). Conservation of natural enemies in cotton role of insect growth regulators in management of Bemisia tabaci. Biol Cont 30: 52-72.

25. Prabhaker N \& Toscano NC (2007). Toxicity of the insect growth regulators, buprofezin and pyriproxyfen, to the glassy-winged

Homalodisca coagulata say (Homoptera: Cicadellidae). Crop Protect 26: 495-502.

26. Wang Y, Gao C, Xu Z, Zhu YC, Zhang J, Li W, Dai D, Lin Y, Zhou W \& Shen J (2008). Buprofezin susceptibility survey, resistance selection and preliminary determination of the resistance mechanism in Nilaparvata lugens (Homoptera: Delphacidae). Pest Manag Sci 64: 1050-1056. 